Widiastuti, L. • T. Pamujiasih · S.J. Rachmawatie

\title{
Pengaruh pupuk organik tandan kosong kelapa sawit terhadap pertumbuhan dan kualitas bunga seruni
}

\section{Effect of organic fertilizer of palm oil empty bunches on the quality of chrysanths flowers}

Diterima : 2 Desember 2018/Disetujui : 22 Maret 2019 / Dipublikasikan : 31 Maret 2019

CDepartment of Crop Science, Padjadjaran University

\begin{abstract}
Chrysanths was most cultivated flower crop in Indonesia at the last five years. It was traded in the domestic and export market. Highly chrysanths demand influence high quality of flower. One of the efforts is giving empty fruit bunches (EFB) of palm oil as organic fertilizer to the growing media. The objectives to be achieved in this study is to determine interaction effect of varieties and types of EFB fertilizer on growth and quality of flowers of chrysanths. This research was conducted from July to October 2018 at Setiya Aji Flower Farm, Bandungan, Semarang, Central Java, with altitude of 800 meters above sea level. The experiment was arranged in a Randomized Block Design (RBD), which consisted of two factors and three replications. First factor was chrysanth varieties that consisted of 3 levels: Selena, Yulimar, and Marimar. Second factor was types of EFB organic fertilizer that consisted of 2 levels: EFB compost 20 t.ha $^{-1}$, and EFB ash 20 t.ha ${ }^{-1}$. The results showed that there were no interaction effect between chrysanth varieties and types of EFB fertilizer on plant height, leaf area, flowering time, harvest time, flower diameter, and vase time of chrysanth. Single effect of variety influenced plant height, flowering time, harvest time, flower diameter, and vase time, while types of EFB fertilizer influenced plant height.
\end{abstract}

Keywords: Seruni • Compost · Ash • Empty palm oil bunches . Flower quality

Dikomunikasikan oleh Jajang Sauman Hamdani

Widiastuti, L. · T. Pamujiasih · S.J. Rachmawatie

Fakultas Pertanian Universitas Islam Batik Surakarta

Korespondensi: airakiranahebat@gmail.com

Nomor kontak: 082328521426.
Sari. Seruni merupakan tanaman bunga yang paling banyak dibudidayakan di Indonesia dalam lima tahun terakhir, baik untuk pasar domestik maupun ekspor. Tingginya permintaan bunga potong menuntut pula tingginya kualitas bunga. Salah satu upaya yang dapat dilakukan adalah dengan pemberian pupuk organik tandan kelapa sawit (TKS) pada media tanam untuk pemenuhan nutrisi dan perbaikan media tanam. Tujuan penelitian ini adalah mempelajari efek interaksi varietas dan macam pupuk organik tandan kosong kelapa sawit terhadap pertumbuhan dan kualitas bunga pada tanaman seruni. Penelitian ini dilaksanakan pada bulan Juli sampai Oktober 2018 di Setiya Aji Flower Farm Bandungan Semarang Jawa Tengah dengan ketinggian tempat 800 meter di atas permukaan laut. Percobaan diatur dalam Rancangan Acak Kelompok (RAK), yang terdiri dari dua faktor dan tiga ulangan. Faktor I adalah varietas seruni yang terdiri dari 3 taraf, yaitu Selena, Yulimar, dan Marimar. Macam pupuk organik TKS terdiri dari 2 taraf yaitu kompos TKS 20 ton/ha dan ATKS 20 ton/ha. Dari hasil penelitian diperoleh tidak terjadi interaksi antara varietas dan macam pupuk organik Tandan Kosong Sawit (TKS) pada tinggi tanaman, luas daun, saat munculnya bunga, umur panen, diameter bunga, dan umur pajang tanaman. Hasil uji mandiri menunjukkan bahwa varietas berpengaruh terhadap tinggi tanaman, saat munculnya bunga, umur panen, diameter bunga, dan umur pajang. Macam pupuk organik TKS menunjukkan berpengaruh secara mandiri terhadap tinggi tanaman.

Kata Kunci: Seruni $\cdot$ Kompos • Abu · Tandan kosong kelapa sawit $\cdot$ Kualitas bunga 


\section{Pendahuluan}

Seruni adalah tanaman bunga hias yang terus mengalami perluasan lahan panennya. Luas panen bunga seruni pada tahun 2015 meningkat sebesar 12,68 persen dibanding tahun 2014, yaitu dari 964,78 hektar pada tahun 2014 menjadi sebesar 1.087,12 hektar pada tahun 2015. Dilihat dari produksinya, bunga seruni menempati urutan pertama yaitu 442,70 juta tangkai, diikuti bunga mawar dengan produksi 188,30 juta tangkai, dan bunga sedap malam dengan produksi 116,69 juta tangkai. Seruni juga menduduki urutan pertama untuk volume ekspor tanaman hias yaitu naik dari 56,23 ton tahun 2014 menjadi 59,63 ton pada tahun 2015. Ekspor seruni antara lain ke negara Malaysia 93,67 \% yaitu sebesar US\$ 664.747, Jepang 6,31 \% yaitu sebesar US\$ 44.800, dan Singapura 0,02\% yaitu sebesar US\$151 (Badan Pusat Statistik, 2016).

Tanaman bunga hias seruni saat ini telah memiliki lebih dari 50 varietas, baik varietas lokal maupun introduksi, dan para petani umumnya menanam menggunakan varietas introduksi, padahal telah banyak varietas lokal hasil pemuliaan Balai Penelitian Tanaman Hias (Balithi) yang tidak kalah baik kualitasnya, seperti kualitas tipe, bentuk, warna, ukuran diameter bunga, dan produktivitas bunganya.

Pertumbuhan dan kualitas bunga seruni sangat dipengaruhi oleh kadar nutrisi yang tersedia dalam media tanam. Kekurangan nutrisi akan menyebabkan hambatan dalam metabolisme tanaman dan pertumbuhan, serta menurunnya kualitas bunga yang dihasilkan. Salah satu usaha penanggulangan yang dapat dilakukan adalah dengan intensifikasi pertanian, yaitu melalui inovasi dengan pemupukan organik untuk mencukupi kebutuhan unsur hara bagi tanaman tanah.

Pemupukan yang utama diperlukan adalah nitrogen, fosfor, dan kalium, jika kekurangan akan berakibat terhadap rendahnya hasil baik dan kualitas maupun kuantitas bunga seruni (Widiastuti, 2016). Pemberian pupuk dasar dan lanjutan secara bertahap diperlukan agar pertumbuhan optimal (Nurmalinda \& Hayati, 2014).

Kalium adalah unsur makro yang berfungsi sebagai aktivator enzim dalam translokasi gula dan fotosintesis. Kalium juga diketahui berperan dalam membuka dan menutupnya stomata. Kalium dipompa keluar dan masuk sel penjaga pada stomata sehingga sangat penting dalam pengaturan potensial air yang memungkinkan terbuka dan tertutupnya stomata. Ion $\mathrm{K}$ mudah didistribusikan dari daun tua ke bagian daun yang lebih muda. Pada tanaman dikotil defisiensi Kalium (K) ditandai dengan gejala klorosis yang diikuti dengan klorosis dalam waktu cepat, terutama di sekitar bagian bercak yang mengering. Pada jagung dan serealia, defisiensi $\mathrm{K}$ ditandai dengan terbentuknya batang yang lemah serta akar tidak kuat sehingga mudah rebah dan terinfeksi penyakit akar (Sutedjo, 2010).

Bentuk pupuk $\mathrm{K}$ yang sering digunakan adalah $\mathrm{KCl}, \mathrm{KNO}_{3}$ atau $\mathrm{K}_{2} \mathrm{SO}_{4}$, ketiganya adalah pupuk sintetik. Pertanian berkelanjutan memberikan prioritas pada pemanfaatan input pertanian yang mampu menjaga kelestarian ekologi. Salah satu input bahan tersebut adalah Tandan Kosong Kelapa Sawit (TKS) yang dijadikan kompos dan abu yang mempunyai kandungan kalium cukup tinggi. Hasil analisis Abu Tandan Kosong Sawit (ATKS) di Laboratorium Ilmu Tanah Universitas Bengkulu yang berasal dari tandan kosong sawit di PT Bio Nusantara Bengkulu Utara menunjukkan kandungan unsur hara pada ATKS adalah 26,3\% K dan 13,74\% P. Abu Janjang Kelapa Sawit dapat diberikan ke tanaman dalam bentuk abu atau tablet. Pemberian berupa tablet lebih praktis dibandingkan dengan bentuk abu. (Bariyanto, et. al., 2015).

Pupuk organik yang diaplikasikan ke lahan akan mengalami dekomposisi dan melepaskan unsur-unsur hara yang diperlukan tanaman seperti unsur-unsur hara makro dan mikro. Kompos TKS merupakan bahan organik yang mengandung unsur hara utama $\mathrm{N}, \mathrm{P}, \mathrm{K}$ dan $\mathrm{Mg}$ serta mengandung unsur hara mikro (Mustaqim, 2016). Dalam rangka pemanfaatan limbah pertanian sebagai sumber hara, berupa kompos dan abu TKS, diharapkan dapat meningkatkan pertumbuhan dan kualitas bunga seruni.

\section{Bahan dan Metode}

Penelitian eksperimen dilaksanakan dari bulan Juli sampai Oktober 2018 di rumah plastik/ greenhouse Setiya Aji Flower Farm Bandungan Semarang Jawa Tengah dengan ketinggian tempat 800 meter di atas permukaan laut. Bahan yang digunakan adalah stek tanaman Seruni, tandan kosong kelapa sawit bentuk abu (ATKS) 
dan kompos (KTKS), fungisida Mankozeb dengan dosis 2g. $\mathrm{L}^{-1}$, dan insektisida Endosulfan dengan dosis $1 \mathrm{~mL} . \mathrm{L}^{-1}$. Alat yang digunakan adalah cangkul; cetok; ember; gembor; hand sprayer; polibag; ajir; kertas karton; kertas perak; pisau; gunting; penggaris; alat tulis; timbangan digital; gelas ukur kapasitas $10 \mathrm{ml}$; serta label.

Rancangan Penelitian menggunakan Rancangan Acak Kelompok (RAK) yang terdiri dari dua faktor dan tiga ulangan. Faktor pertama adalah varietas seruni $(\mathrm{V})$ yang terdiri dari 3 taraf, yaitu : Selena, Yulimar dan Marimar. Faktor kedua adalah macam pupuk organik (P) yang terdiri dari 2 taraf, yaitu abu tandan kosong kelapa sawit (ATKS : 20 ton ha-1.) dan kompos tandan kosong kelapa sawit (KTKS : 20 ton ha-1). Data dianalisis dengan menggunakan analisis varian. Apabila ada beda nyata antar perlakuan maka hasil analisis diuji lanjut dengan uji jarak berganda Duncan 5\%. Data yang menunjukkan kualitas tanaman dianalisis regresi.

\section{Hasil dan Pembahasan}

Selama di pembibitan, stek seruni tumbuh dengan baik dan seluruhnya dapat berakar pada 2 minggu setelah tanam (MST). Seruni masih memperlihatkan pertumbuhan yang seragam pada umur 15 hari setelah tanam (HST), namun perbedaan tinggi tanaman mulai tampak setelah tanaman seruni dipotong pucuknya (pinching), dan pada saat penambahan cahaya malam hari dihentikan (umur 30 hst).

Tanaman seruni tidak memperlihatkan gejala penyakit secara serius, namun demikian pencegahan dilakukan dengan cara penyemprotan tanaman dengan fungisida Mankozeb dengan dosis $2 \mathrm{~g} . \mathrm{L}^{-1}$ dan insektisida Endosulfan dengan dosis $1 \mathrm{~mL} . \mathrm{L}^{-1}$ pada bagian bawah daun tiap satu minggu.

Hasil analisis varians menunjukkan tidak terjadi interaksi antara varietas tanaman bunga hias seruni dan macam pupuk organik TKS pada semua parameter pengamatan. Hal ini diduga karena ketiga varietas adalah dalam satu turunan varietas yaitu varietas Fiji, sehingga ketiga varietas tersebut tidak menunjukkan perbedaan respon terhadap pupuk organik TKS semua parameter yang diamati, sehingga tidak ada interaksi antara varietas dan pupuk organik TKS (Tabel 1, 2, dan 3).
Tabel 1. Pengaruh Varietas Seruni dan Macam Pupuk Organik Tangkai Kosong Kelapa Sawit terhadap Tinggi Tanaman $(\mathrm{cm})$ dan Luas Daun (cm).

\begin{tabular}{lcc}
\hline Perlakuan & $\begin{array}{c}\text { Tinggi } \\
\text { Tanaman }\end{array}$ & Luas Daun \\
\hline Varietas & & \\
\hline Selena & $79,16 \mathrm{a}$ & $50,19 \mathrm{a}$ \\
Marimar & $82,98 \mathrm{ab}$ & $56,18 \mathrm{a}$ \\
Yulimar & $86,20 \mathrm{~b}$ & $59,68 \mathrm{a}$ \\
\hline Pupuk Organik TKS & & \\
\hline Kompos TKS & $88,76 \mathrm{p}$ & $54,38 \mathrm{p}$ \\
Abu TKS & $94,88 \mathrm{q}$ & $58,11 \mathrm{p}$ \\
\hline Interaksi & $(-)$ & $(-)$ \\
\hline
\end{tabular}

Keterangan : Angka diikuti huruf sama pada kolom yang sama tidak berbeda nyata pada uji jarak berganda Duncan 5\%. Tanda menunjukkan ada interaksi antar perlakuan.

Hasil uji mandiri menunjukkan varietas tanaman berpengaruh terhadap tinggi tanaman, namun tidak menunjukkan pengaruh terhadap luas daun. Macam pupuk organik TKS berpengaruh terhadap tinggi tanaman, namun tidak berpengaruh terhadap luas daun tertinggi. Varietas Yulimar lebih tinggi daripada varietas Selena, namun tidak berbeda dengan varietas Marimar. Hal ini diduga disebabkan karena varietas Yulimar adalah turunan esensial dari varietas Fiji White yang memiliki keunggulan yaitu batang dan tangkai bunga yang tebal, sangat mendukung ukuran bunga yang besar, serta perakaran dalam sehingga penyerapan hara lebih cepat dan optimal yang akhirnya memacu tinggi tanaman. Tinggi tanaman ini nantinya akan menentukan panjang tangkai bunga potong seruni. Semakin tinggi tanaman maka semakin panjang tangkai bunga yang dihasilkan. Pertumbuhan dan kualitas tanaman seruni sangat dipengaruhi oleh kadar hara yang tersedia dan dapat diserap oleh tanaman. Kekurangan unsur hara akan menyebabkan hambatan dalam pertumbuhan dan gejala-gejala lain yang dapat mengganggu kualitas pertumbuhan tanaman dan pada akhirnya menurunkan penampilan dan kualitas bunga yang dihasilkan (Setiadi, dkk, 2018).

Abu tandan kosong menghasilkan tinggi tanaman paling tinggi dibandingkan kompos. Hal ini diduga abu tandan kosong lebih cepat tersedia sehingga dapat diserap oleh tanaman dalam waktu yang cepat dibandingkan kompos. Oleh karena itu, pertumbuhan tanaman lebih cepat akibat hara banyak tersedia (Widiastuti, 2012). 
Tabel 3. Pengaruh Varietas Seruni dan Macam Pupuk Organik Tangkai Kosong Kelapa Sawit Terhadap Saat Munculnya Bunga (Hari) dan Umur Panen (Hari).

\begin{tabular}{lll}
\hline Perlakuan & $\begin{array}{l}\text { Saat } \\
\text { munculnya } \\
\text { bunga }\end{array}$ & Umur Panen \\
\hline Varietas & $30,92 \mathrm{a}$ & $63,00 \mathrm{a}$ \\
Selena & $64,88 \mathrm{~b}$ & $98,00 \mathrm{~b}$ \\
Marimar & $67,79 \mathrm{~b}$ & $98,33 \mathrm{~b}$ \\
Yulimar & $58,08 \mathrm{p}$ & $90,80 \mathrm{p}$ \\
\hline Pupuk Organik TKS & $91,07 \mathrm{p}$ \\
\hline Kompos TKS & $60,08 \mathrm{p}$ & $(-)$ \\
\hline Interaksi & $(-)$ & sas
\end{tabular}

Keterangan : Angka diikuti huruf sama menunjukkan tidak berbeda nyata pada uji Duncan 5\%. Tanda (+) menunjukkan ada interaksi antar perlakuan.

Pada tabel 3 hasil uji mandiri menunjukkan varietas tanaman berpengaruh terhadap saat munculnya bunga dan umur panen tertinggi pada varietas Marimar dan Yulimar. Namun, macam pupuk organik TKS berpengaruh tidak nyata terhadap umur munculnya bunga dan umur panen. Hal ini diduga karena semakin tersedianya unsur hara yang dibutuhkan tanaman maka akan semakin banyak yang dimanfaatkan oleh tanaman untuk pertumbuhannya, sehingga akan terjadi peningkatan proses metabolisme, utamanya peningkatan fotosintesis.

Kompos mampu menggemburkan tanah sehingga dapat mempermudah perkembangan akar dan meningkatkan kemampuannya dalam penyerapan hara secara optimal (Onggo, dkk, 2017). Kompos juga sangat baik dalam memperbaiki struktur tanah, sifat fisik dan kimia tanah (Elmizan, 2014).

Pada percobaan ini menggunakan penambahan pupuk organik TKS dimana pupuk ini mengandung unsur makro dan mikro yang dibutuhkan oleh pertumbuhan tanaman serta pupuk organik TKS ini juga mengandung gibberellin. Zat pengatur tumbuh gibberellin merupakan zat yang dapat memacu pertumbuhan bunga pada tanaman yang dengan dosis yang sama pada setiap tanaman. Hal ini diduga membuat bunga muncul pertama kali serentak pada setiap jenis media tanam yang di cobakan, karena kandungan unsur hara yang terkandung pada setiap komposisi media tanam yang dicobakan hampir sama dan dengan penambahan pupuk yang sama pada setiap tanaman serta didukung oleh kondisi lingkungan yang mendukung untuk pertumbuhan dan pembungaan tanaman seruni (Widiastuti, 2014).

Tabel 4.Pengaruh varietas seruni dan macam pupuk organik tangkai kosong kelapa sawit terhadap Diameter Bunga $\left(\mathrm{cm}^{3}\right)$ dan Umur Pajang Tanaman (hari).

\begin{tabular}{|c|c|c|}
\hline Perlakuan & $\begin{array}{l}\text { Diameter } \\
\text { Bunga }\end{array}$ & Umur Pajang \\
\hline \multicolumn{3}{|l|}{ Varietas } \\
\hline Selena & $10.42 \mathrm{a}$ & $5,38 \mathrm{~b}$ \\
\hline Marimar & $12,38 \mathrm{~b}$ & $6,00 a$ \\
\hline Yulimar & $12,57 \mathrm{~b}$ & $11,00 \mathrm{~b}$ \\
\hline \multicolumn{3}{|c|}{ Pupuk Organik TKS } \\
\hline Kompos TKS & $12,02 \mathrm{p}$ & $7,66 \mathrm{p}$ \\
\hline Abu TKS & $12,05 \mathrm{p}$ & $7,67 \mathrm{p}$ \\
\hline Interaksi & $(-)$ & $(-)$ \\
\hline \multicolumn{3}{|c|}{$\begin{array}{l}\text { Keterangan : Angka diikuti huruf sama } \\
\text { menunjukkan tidak berbeda nyata pada uji Duncan } \\
5 \% \text {. Tanda }(+) \text { menunjukkan ada interaksi antar } \\
\text { perlakuan. }\end{array}$} \\
\hline
\end{tabular}

Tabel 4 Hasil uji mandiri menunjukkan varietas tanaman berpengaruh terhadap diameter bunga dan umur pajang bunga. Diameter bunga terbesar diperoleh varietas Marimar dan Yulinar, sementara umur pajang terlama pada varietas Selena dan Yulinar. Macam pupuk organik TKS berpengaruh tidak nyata terhadap diameter bunga dan umur pajang bunga. Hal ini diduga kandungan auksin yang rendah dalam tanaman, salah satunya menyebabkan aktivitas akar menurun, sehingga penyerapan air berkurang yang mengakibatkan turgiditas sel pun menurun, sehingga jumlah air sel yang ditranspirasi sedikit, maka tanaman menjadi cepat layu dan umur pajang tanaman semakin pendek (Handajaningsih dan Wibisono, 2009).

\section{Kesimpulan dan Saran}

Tidak terjadi interaksi antara macam varietas dan macam pupuk organik Tandan Kosong Sawit (TKS) terhadap tinggi tanaman, luas daun, saat munculnya bunga, umur panen, diameter bunga, dan umur umur pajang tanaman.

Hasil uji mandiri varietas menunjukkan bahwa varietas berpengaruh terhadap tinggi tanaman, saat munculnya bunga, umur panen, 
diameter bunga, dan umur pajang. Varietas Marimar dan Yulimar memberikan umur muncul bunga dan umur panen paling panjang serta diameter bunga paling besar. Abu tandan kosong sawit memberikan tinggi tanaman yang paling baik.

\section{Ucapan Terima Kasih}

Terimakasih penulis ucapkan kepada :

1. Universitas Islam Batik Surakarta

2. Setiya Aji Flower Farm Bandungan Semarang Jawa Tengah.

\section{Daftar Pustaka}

Badan Pusat Statistik. 2016. Statistik Tanaman Hias Indonesia. Statistik Tanaman Hias Indonesia 2015 , Badan Pusat Statistik. 1100.

Bariyanto, Nelvia, \& Wardati. 2015. Pengaruh pemberian kompos tandan kosong kelapa sawit (Tkks) pada pertumbuhan bibit kelapa sawit (Elaeis guineensis Jacq) di main-nursery pada medium subsoil ultisol. Jurnal Online Mahasiswa Fakultas Pertanian. 2 (1).

Creswell, J., W. 2012. Research Design Pendekatan Kualitatif, Kuantitatif dan Mixed. Pustaka Pelajar. Yogyakarta.

Handajaningsih, M., \&Wibisono, T. 2009. Pertumbuhan dan pembungaan krisan dengan pemberian abu janjang kelapa sawit sebagai sumber kalium. Jurnal Akta Agrosia. 12 (1), 8-14.

Mustaqim, R., Armaini., A.E. Yulia. 2016. Pengaruh Pemberian Kompos Tandan
Kosong Kelapa Sawit dan Pupuk NPK Terhadap Pertumbuhan dan Produksi Tanaman Melon (Cucumis melo L). Jurnal Online Mahasiswa Fakultas Pertanian. 2 (1), 1-13.

Nurmalinda dan Hayati. 2014. Preferensi konsumen terhadap krisan bunga potong dan pot. Jurnal Hortikultura. 24 (4). 363-372.

Onggo, T.M, Kusumiyati, A. Nurfitriana. Pengaruh penambahan arang sekam dan ukuran polybag terhadap pertumbuhan dan hasil tanaman tomat kultivar 'valouro' hasil sambung batang. Jurnal Kultivasi, 16 (1), 298-304.

Setiadi, D,. Noertjahyani, dan Suparman. Perbedaan kualitas dan vase life bunga krisan akibat aplikasi macam pupuk organik dengan variasi jarak tanam. Jurnal Kultivasi. 17 (1).587-595.

Sutedjo, M. M. 2010. Pupuk Dan Cara Pemupukan. Rineka Cipta. Jakarta.

Widiastuti, L. 2016. Macam media dan sistem irigasi untuk pengakaran stek pucuk krisan standar (Chrysanthemum morifolium). Agronomika, 10 (02).

Widiastuti, L. 2014. Pengaruh umur bibit dan konsentrasi $\mathrm{ga}_{3}$ terhadap pembungaan tanaman krisan standar (Chrysanthemum morifolium R). Agronomika, 09 (02).

Widiastuti, L. 2012. Pengaruh umur bibit dan konsentrasi ga3 terhadap pertumbuhan tanaman krisan standar (Chrysanthemum morifolium R Var. Tmw). Agronomika, 07 (01).

Widiastuti, L., Tohari, \& Sulistyaningsih, E. 2004. Pengaruh intensitas cahaya dan kadar daminosida terhadap iklim Mikro Dan Pertumbuhan Tanaman Krisan Dalam Pot. Ilmu Pertanian, 11 (02), 35-42. 